\title{
Crystal Structure and Luminescence Properties of a Thermally Stable Single-Phase White Emitting Phosphor $\mathrm{CaSr}_{2}\left(\mathrm{PO}_{4}\right)_{2}: \mathrm{Dy}^{3+}, \mathrm{Li}^{+}$
}

\section{Qingfeng Guo ( $\nabla$ qfguo@cugb.edu.cn )}

China University of Geosciences Beijing

\section{Yuying Chen}

China University of Geosciences Beijing

\section{Qiang Hao}

The University of Sydney

\section{Stefan Lis}

Adam Mickiewicz University: Uniwersytet im Adama Mickiewicza w Poznaniu

\section{Haikun Liu}

Dongguan University of Technology

\section{Marcin Runowski}

Adam Mickiewicz University: Uniwersytet im Adama Mickiewicza w Poznaniu

\section{Lefu Mei}

China University of Geosciences Beijing

\section{Libing Liao}

China University of Geosciences Beijing

\section{Research Article}

Keywords: CaSr2(PO4)2, Phosphor, Dy3+, Thermal stability

Posted Date: June 3rd, 2021

DOl: https://doi.org/10.21203/rs.3.rs-577287/v1

License: (c) (i) This work is licensed under a Creative Commons Attribution 4.0 International License. Read Full License 


\section{Abstract}

Single-phase $\mathrm{CaSr}_{2}\left(\mathrm{PO}_{4}\right)_{2}: \mathrm{Dy}^{3+}, \mathrm{Li}^{+}$phosphors were prepared using the high-temperature solid-state method in the air. To characterize the luminescence properties of the synthesized phosphors, Powder Xray diffraction patterns (XRD), scanning electron microscopy images (SEM), photoluminescence spectra, and concentration-dependent emission spectra were measured to characterize the luminescence properties of the synthesized phosphors. The results showed that the $\mathrm{CaSr}_{2}\left(\mathrm{PO}_{4}\right)_{2}: \mathrm{Dy}^{3+}, \mathrm{Li}^{+}$phosphors exhibited white luminescence, and the emission spectra of the phosphors consisted of two sharp peaks at $\approx 486$ and $\approx 578 \mathrm{~nm}$ (the most intense one). The optimum concentration of $\mathrm{Dy}^{3+}$ doping was determined to $0.06 \mathrm{~mol} . \%$. On the basis of the Dexter's theory, the mechanism of energy transfer between the $\mathrm{Dy}^{3+}$ ions was determined to dipole-dipole interactions. The results of the temperature-dependent luminescence confirmed that the as-prepared phosphors are proved to be promising UV-convertible material capable of white light emitting in UV-LEDs due to its excellent thermal stability and luminescence properties. Luminescence intensity and decay time of the $\mathrm{CaSr}_{2}\left(\mathrm{PO}_{4}\right)_{2}: \mathrm{Dy}^{3+}, \mathrm{Li}^{+}$phosphors were improved remarkably with the addition of charge compensators ( $\mathrm{Li}^{+}$ions), which would promote their applications in white light-emitting diodes based on the near-UV chip.

\section{Introduction}

In recent years, white light-emitting diodes (LEDs) have been widely applied to various purposes due to their superior performance, like device indicators, automobile headlights and general illumination [1-3]. Commercial manufacture of white LEDs is typically achieved through coating a yellow-emitting phosphor on a blue LED chip, because of its lower cost and higher technical development [4,5]. However, these white LEDs exhibit a low color rendering index $(\mathrm{CRI}<80)$ and high correlated color temperature $(\mathrm{CCT})$ due to the deficiency of the red component [6]. Nowadays, many researchers have attempted to obtain the white LEDs by combining a near-UV LED chip with red, green and blue-emitting (RGB) phosphors $[7,8]$. These RGB systems, however, are expensive to manufacture, and may have a low efficiency of blue emission due to its reabsorption by the red and green-emitting phosphors [9-11]. Therefore, efficient, durable, and single-phase white light-emitting phosphors attract increasing research interest because of these disadvantages.

Until now, various single-phase white phosphors have been explored, such as $\mathrm{Eu}^{2+}-\mathrm{Mn}^{2+}, \mathrm{Mn}^{2+}-\mathrm{Tb}^{3+}, \mathrm{Ce}^{3+}$ $\mathrm{Tb}^{3+}, \mathrm{Eu}^{2+}-\mathrm{Eu}^{3+}$ co-doped silicates, phosphates and so on [12-16]. However, energy transfer between activators is needed for white light in these systems, which results in the serious loss of energy. Luminescence spectrum of trivalent dysprosium $\left(\mathrm{Dy}^{3+}\right)$ ions consists of two intense emission bands in the blue (470-500 nm) and yellow regions (560-600 nm), which correspond to their ${ }^{4} \mathrm{~F}_{9 / 2}-{ }^{6} \mathrm{H}_{13 / 2}$ and ${ }^{4}$ $\mathrm{F}_{9 / 2}-{ }^{6} \mathrm{H}_{15 / 2}$ electron transitions, respectively $[17,18]$. By adjusting the intensity ratio of yellow emission to blue emission, it is possible to obtain near-white light emission [19]. Particularly, the luminescence properties of $\mathrm{Dy}^{3+}$-doped phosphate phosphors have attracted a lot of attention due to their significant 
use in solid state light, especially in the case of white light emission. Therefore, doping Dy ${ }^{3+}$ into the appropriate host is an important strategy to obtain single-phase white light-emitting phosphors. For instance, $\mathrm{CdSiO}_{3}: \mathrm{Dy}^{3+}$ [20], $\mathrm{M}_{2} \mathrm{Si}_{5} \mathrm{~N}_{8}: \mathrm{Dy}^{3+}$ [21], $\mathrm{Ca}_{3}\left(\mathrm{PO}_{4}\right)_{2}: \mathrm{Dy}^{3+}$ [22], $\mathrm{MZr}_{4}\left(\mathrm{PO}_{4}\right)_{6}: \mathrm{Dy}^{3+}$ [23], $\mathrm{GdVO}_{4}: \mathrm{Dy}^{3+}$ [24], $\mathrm{SrAl}_{2} \mathrm{O}_{4}: \mathrm{Dy}^{3+}$ [25], $\mathrm{GdSCO}_{3}: \mathrm{Dy}^{3+}[26]$, and $\mathrm{Y}_{2} \mathrm{O}_{3}: \mathrm{Dy}^{3+}$ [27] have been extensively studied as white-light emitting phosphors for UV chip-based white LEDs. On the basis of literature studies and the summary of knowledge, we found that similar to the $\mathrm{M}_{3}\left(\mathrm{PO}_{4}\right)_{2}(\mathrm{M}=\mathrm{Ca}, \mathrm{Sr}, \mathrm{Ba})$ structure [28-29], among which $\mathrm{CaSr}_{2}\left(\mathrm{PO}_{4}\right)_{2}$ is also a suitable host for phosphors [30]. The effect of $\mathrm{Li}^{+}, \mathrm{Na}^{+}$and $\mathrm{K}^{+}$co-doping on the luminescence enhancement of $\mathrm{CaSr}_{2}\left(\mathrm{PO}_{4}\right)_{2}: \mathrm{Dy}^{3+}$ phosphors for white light-emitting diodes has been reported [31]. However, the focus was on the effect of the phosphor reinforcing agent. Moreover, the concentration quenching and thermal stability of $\mathrm{Dy}^{3+}$ were not studied in $\mathrm{CaSr}_{2}\left(\mathrm{PO}_{4}\right)_{2}$. Hence, to study in detail the luminescence properties and the concentration quenching, the thermal stability of Dy ${ }^{3+}$ in $\mathrm{CaSr}_{2}\left(\mathrm{PO}_{4}\right)_{2}$ is essential.

Here, a series of $\mathrm{CaSr}_{2-2 x}\left(\mathrm{PO}_{4}\right)_{2}: x \mathrm{Dy}^{3+}, x \mathrm{Li}^{+}$phosphors was synthesized by a high-temperature solid-state reaction method in an air atmosphere. The samples were characterized by X-ray diffraction (XRD), scanning electron microscopy (SEM), photoluminescence excitation (PLE) and emission (PL) spectra, including time-resolved spectroscopy (luminescence decay curves). The XRD pattern of the $\mathrm{CaSr}_{2}\left(\mathrm{PO}_{4}\right)_{2}$ phase is similar to the whitlockite mineral that crystallizes in the space group R3c. In addition, the asprepared phosphors have good thermal stability, confirmed by temperature-dependent emission spectra. The obtained results indicate that the as-prepared $\mathrm{CaSr}_{2}\left(\mathrm{PO}_{4}\right)_{2}: \mathrm{Dy}^{3+}, \mathrm{Li}^{+}$phosphor can act as a UV convertible, white phosphor for $w$-LEDs.

\section{Experimental Section}

\subsection{Materials and synthesis}

Powder samples $\mathrm{CaSr}_{2-2 x}\left(\mathrm{PO}_{4}\right)_{2}: x \mathrm{Dy}^{3+}, x \mathrm{Li}^{+}(x=0-0.4)$ were synthesized by a high temperature solid-state method. The starting materials, $\mathrm{CaCO}_{3}(99.9 \%), \mathrm{SrCO}_{3}(99.9 \%), \mathrm{Li}_{2} \mathrm{CO}_{3}(99.9 \%),\left(\mathrm{NH}_{4}\right)_{2} \mathrm{HPO}_{4}(99.9 \%)$, and $\mathrm{Dy}_{2} \mathrm{O}_{3}(99.999 \%)$ were purchased from Aldrich. First, according to stoichiometric ratios, these starting materials were mixed and thoroughly ground in an agate mortar. The pre-sintered samples were then transferred evenly to a tube furnace and calcined at $800{ }^{\circ} \mathrm{C}$ for $1 \mathrm{~h}$ of decomposition of the calcium carbonate and strontium carbonate in air. Finally, the as-prepared powders were calcined again at 1250 ${ }^{\circ} \mathrm{C}$ for $5 \mathrm{~h}$ in an air atmosphere, and the furnace was cooled down to room temperature before their removal.

\subsection{Characterization}

The obtained $\mathrm{CaSr}_{2-2 x}\left(\mathrm{PO}_{4}\right)_{2}: x \mathrm{Dy}^{3+}, x \mathrm{Li}^{+}$phosphors were studied by XRD analysis (XD-3, PGENERAL, China) in the $2 \theta$ range of $10^{\circ}$ to $70^{\circ}$, with Cu Ka radiation $(\lambda=0.15406 \mathrm{~nm})$ operating at $40 \mathrm{kV}$ and $40 \mathrm{~mA}$. 
The PL and PLE spectra of the phosphors were measured on a F-4600 spectrofluorometer (HITACHI, Japan) with a photomultiplier tube operating at $500 \mathrm{~V}$, and a $150 \mathrm{~W}$ Xe lamp used as an excitation source. A $400 \mathrm{~nm}$ cut-off filter was used to eliminate the second-order emission. Temperature-dependent $\mathrm{PL}$ spectra were also measured using the same spectrofluorometer with the home-made heating controller. The $\mathrm{CaSr}_{2}\left(\mathrm{PO}_{4}\right)_{2}$ were observed by SEM using the HitachiS-520 instrument. The roomtemperature luminescence decay curves were recorded with a spectrofluorometer (Horiba, JobinYvon TBXPS), using a tunable pulse laser radiation as the excitation source.

\section{Results And Discussion}

\subsection{Crystal structure}

The valence charge is unbalanced when $\mathrm{Mn}^{+}$ions are substituted by $\mathrm{M}^{(\mathrm{n}+1)}$. This is undesirable for the phosphor materials and decreases the luminescence intensity. To avoid the charge unbalance and the formation of vacancy in the sample, $\mathrm{Li}^{+}$ions were employed as charge compensators and added along with $\mathrm{Dy}^{3+}$ ions. The mechanism of charge compensation is based on the fact that two $\mathrm{Sr}^{2+}$ ions are replaced by one $\mathrm{Dy}^{3+}$ ion and one $\mathrm{Li}^{+}$ion. Therefore, the crystallinity of $\mathrm{CaSr}_{2}\left(\mathrm{PO}_{4}\right)_{2}: \mathrm{Dy}^{3+}, \mathrm{Li}^{+}$improves because the doping with $\mathrm{Li}^{+}$lowers the crystallization temperature. The XRD patterns of the synthesized $\mathrm{CaSr}_{2-2 x}\left(\mathrm{PO}_{4}\right)_{2}: x \mathrm{Dy}^{3+}, x \mathrm{Li}^{+}(x=0.01,0.03,0.06,0.12,0.18,0.24,0.27$ and 0.3$)$ are shown in Fig. 1 . The XRD patterns of the synthesized $\mathrm{CaSr}_{2-1.5 x}\left(\mathrm{PO}_{4}\right)_{2}: \mathrm{xDy}^{3+},(x=0.01,0.03,0.05,0.07,0.09,0.12,0.15$ and 0.18$)$ and $\mathrm{CaSr}_{2}\left(\mathrm{PO}_{4}\right)_{2}$ are shown in Fig. 2 . It is clearly seen that all the XRD patterns can be well fitted with the standard patterns of the $\mathrm{Ca}_{3}\left(\mathrm{PO}_{4}\right)_{2}$ (JCPDS no. 09-0169) belonging to the trigonal crystal system, with the space group of R3c(161). The introduction of $\mathrm{Li}^{+}$did not have any significant influence on the structure of the as-prepared samples, which suggests that all samples were crystallized in a single phase. All diffraction peaks shifted to the smaller $2 \theta$ angle side (larger d-spacing, i.e. interplanar distances), which can be ascribed to the substitution of $\mathrm{Ca}^{2+}$ by larger $\mathrm{Sr}^{2+}$. $\mathrm{Dy}^{3+}$ and $\mathrm{Li}^{+}$ions have been successfully embedded into the crystal lattice, and also the $\mathrm{Dy}^{3+}$ and $\mathrm{Li}^{+}$dopant ions had negligible influence on the structure of the host $\mathrm{CaSr}_{2}\left(\mathrm{PO}_{4}\right)_{2}$ in varying amounts of doping.

The crystal structure of $\mathrm{CaSr}_{2}\left(\mathrm{PO}_{4}\right)_{2}$ and different coordination environments for $\mathrm{Ca} / \mathrm{Sr}$ atoms have already been discussed in the literature. [32] The crystalline structure of $\mathrm{CaSr}_{2}\left(\mathrm{PO}_{4}\right)_{2}$ is a result of the lattice deformation of $\mathrm{Ca}_{3}\left(\mathrm{PO}_{4}\right)_{2}$ by partial substitution of $\mathrm{Ca}^{2+}$ with $\mathrm{Sr}^{2+}$. In the crystal structure of $\mathrm{CaSr}_{2}\left(\mathrm{PO}_{4}\right)_{2}$, the $\mathrm{Ca}^{2+}\left(\mathrm{Sr}^{2+}\right)$ ions are distributed between five crystallographic sites, four of which can be occupied by both $\mathrm{Ca}^{2+}$ and $\mathrm{Sr}^{2+}$ ions in various ways defined by chemical composition, and one site only can be occupied by $\mathrm{Ca}^{2+}$ ions, which are too small to be occupied by $\mathrm{Sr}^{2+}$ ions. If the number of $\mathrm{Sr}^{2+}$ ions continues to increase in the $\mathrm{Ca}_{2-x} \mathrm{Sr}_{1+x}\left(\mathrm{PO}_{4}\right)_{2}$ structure, the replacement of $\mathrm{Ca}^{2+}$ by $\mathrm{Sr}^{2+}$ in all these compounds does not change the space group, and the crystal structure remains unchanged. If all crystallographic sites are occupied by $\mathrm{Sr}^{2+}$ ions, the structure of $\mathrm{CaSr}_{2}\left(\mathrm{PO}_{4}\right)_{2}$ would change to $\mathrm{Sr}_{3}\left(\mathrm{PO}_{4}\right)_{2}$, 
which is different from the former one. In the crystal structure of $\mathrm{Sr}_{3}\left(\mathrm{PO}_{4}\right)_{2}$ there are two nonequivalent crystallographic sites for the $\mathrm{Sr}^{2+}$ ions ( $\mathrm{Sr} 1$ and $\left.\mathrm{Sr} 2\right)$. The $\mathrm{Sr} 1$ atoms are located on the threefold axis, and show 10 coordination sites with 6 oxygen atoms as nearest neighbors belonging to the $\mathrm{PO}_{4}$ group and site symmetry C3v slightly closer than other coordination sites with 8 oxygen atoms. The other $\mathrm{Sr} 2$ atoms in the unit cell show an octahedral configuration, coordinated with eight oxygen atoms. The Sr2 site has 12 coordination numbers and is the largest site in this structure from the $\mathrm{PO}_{4}$ tetrahedral on the six-fold axis.

It was found that the formation of $\mathrm{CaSr}_{2}\left(\mathrm{PO}_{4}\right)_{2}$ structure is more favorable than the formation of $\mathrm{Sr}_{3}\left(\mathrm{PO}_{4}\right)_{2}$ [33]. This phenomenon can be explained by the fact that the formation energy of $\mathrm{CaSr}_{2}\left(\mathrm{PO}_{4}\right)_{2}$ from $\mathrm{Ca}_{2} \mathrm{Sr}\left(\mathrm{PO}_{4}\right)_{2}$ is lower by $17.34 \mathrm{eV}$ than the formation energy of $\mathrm{CaSr}_{2}\left(\mathrm{PO}_{4}\right)_{2}$ from $\mathrm{Sr}_{3}\left(\mathrm{PO}_{4}\right)_{2}$ [34]. In the crystal structure of $\mathrm{CaSr}_{2}\left(\mathrm{PO}_{4}\right)_{2}$, the $\mathrm{Ca}^{2+} / \mathrm{Sr}^{2+}$ ions are distributed between five crystallographic sites - all of them are occupied by both $\mathrm{Ca}^{2+}$ and $\mathrm{Sr}^{2+}$ ions in various ways. The $\mathrm{Sr} 1 / \mathrm{Ca} 1, \mathrm{Sr} 2 / \mathrm{Ca} 2, \mathrm{Sr} 3 / \mathrm{Ca} 3$, $\mathrm{Sr} 4 / \mathrm{Ca} 4$ and Sr5/Ca5 positions are coordinated with six, six, seven, three and six oxygen atoms, respectively. It is worth noting that the $\mathrm{Ca} 4$ is threeOfold coordinated, suggesting weak bonding and the formation of crystal defects.

To investigate the composition and morphology of the material, the $\mathrm{CaSr}_{1.88}\left(\mathrm{PO}_{4}\right)_{2}: 0.06 \mathrm{Dy}^{3+}, 0.06 \mathrm{Li}^{+}$ phosphor was selected as a representative example for measurements. Fig. 3(a) displays the results elemental analysis of the sample measured by the EDS method, and the inset shows SEM images of the $\mathrm{CaSr}_{1.88}\left(\mathrm{PO}_{4}\right)_{2}: 0.06 \mathrm{Dy}^{3+}, 0.06 \mathrm{Li}^{+}$sample with elemental mapping of $\mathrm{CaSr}_{1.88}\left(\mathrm{PO}_{4}\right)_{2}: 0.06 \mathrm{Dy}^{3+}, 0.06 \mathrm{Li}^{+}$ phosphor provided in Fig. 3(b). The EDS results indicate that the synthesized phosphor is composed of $\mathrm{Ca}, \mathrm{Sr}, \mathrm{P}, \mathrm{O}$, and Dy, which is consistent with the composition of $\mathrm{CaSr}_{1.88}\left(\mathrm{PO}_{4}\right)_{2}: 0.06 \mathrm{Dy}^{3+}, 0.06 \mathrm{Li}^{+}$ material. Besides, the results revealed the contents of each element in Table 1. The SEM image reveals that the as-prepared samples are well-crystallized. The substances synthesized by solid-state method are usually agglomerated, but the sample obtained consist of irregular crystal sizes, which meet well the requirements of phosphor used in $w$-LEDs. Moreover, the mapping results showed that the distribution of the elements in this material is very uniform.

\subsection{Photoluminescence properties}

Fig. 4 depicts the excitation spectrum $\left(\lambda_{\text {em }}=578 \mathrm{~nm}\right)$ of various Dy ${ }^{3+}$-doped $\mathrm{CaSr}_{2}\left(\mathrm{PO}_{4}\right)_{2}$ phosphors. The excitation spectrum of the $\mathrm{Dy}^{3+}$ ion, monitored at $580 \mathrm{~nm}$ emission (corresponding to the ${ }^{4} \mathrm{~F}_{9 / 2} \rightarrow{ }^{6} \mathrm{H}_{13 / 2}$ transition), consists of several sharp peaks centered at 299, 328, 351, 390, and $455 \mathrm{~nm}$, which are assigned to the $\mathrm{f}-\mathrm{f}$ transitions of $\mathrm{Dy}{ }^{3+}$ from its ground state ${ }^{6} \mathrm{H}_{15 / 2}$ to the excited states ${ }^{4} \mathrm{M}_{17 / 2},{ }^{6} \mathrm{P}_{7 / 2}$, ${ }^{6} \mathrm{P}_{3 / 2},{ }^{4} \mathrm{~F}_{7 / 2}$ and ${ }^{4} \mathrm{G}_{11 / 2}$, respectively. Excitation peaks between 320 and $400 \mathrm{~nm}$ indicate that $\mathrm{CaSr}_{2}\left(\mathrm{PO}_{4}\right)_{2}: \mathrm{Dy}^{3+}$ phosphors can be effectively excited by near-UV LED-chips. Fig. 5 shows the emission spectra of the $\mathrm{CaSr}_{2-2 x}\left(\mathrm{PO}_{4}\right)_{2}: x \mathrm{Dy}^{3+}, \mathrm{LLi}^{+}(x=0.01-0.3)$ phosphors, measured at room temperature, wavelength with the excitation of $403 \mathrm{~nm}\left({ }^{6} \mathrm{H}_{15 / 2} \rightarrow{ }^{6} \mathrm{P}_{3 / 2}\right)$; the inset shows the dependence of the 
emission intensity at 486 and $578 \mathrm{~nm}$ on the $\mathrm{Dy}^{3+}$ doping concentration. Different from other $\mathrm{Dy}^{3+}$ - doped phosphors [35], as the $\mathrm{Dy}^{3+}$ amount increases, the emission intensity increases and reaches a maximum at $6 \mathrm{~mol} . \% \mathrm{Dy}^{3+}$ doping content, which is considered as the optimum concentration. A higher $\mathrm{Dy}^{3+}$ ion concentration results in a reduction of the luminescence intensity associated with concentration quenching phenomenon. This is because when the concentration of Dy ${ }^{3+}$ increases, the distance between the ions reduces and enhances the energy transfer cross-relaxation processes between the dopant ions.

Fig. 6(a) shows the emission spectra of the $\mathrm{CaSr}_{2-2 x}\left(\mathrm{PO}_{4}\right)_{2}: x \mathrm{Dy}^{3+}, \mathrm{LLi}^{+}(x=0.01$ and 0.03$)$ and $\mathrm{CaSr}_{2-}$ ${ }_{2 x}\left(\mathrm{PO}_{4}\right)_{2}: x \mathrm{Dy}^{3+}{ }^{+}, \mathrm{Na}^{+}(x=0.01$ and 0.03$)$ phosphors, under $351 \mathrm{~nm}$ excitation. The emission spectra of $\mathrm{CaSr}_{2}\left(\mathrm{PO}_{4}\right)_{2}: 0.03 \mathrm{Dy}^{3+}, \mathrm{Li}^{+} / \mathrm{Na}^{+}$samples include some peaks centered at 486 and $578 \mathrm{~nm}$, which are similar to those mentioned in Fig. 5. This indicates that co-doping with $\mathrm{Li}^{+}$enhances the luminescence intensity of phosphors and it is more effective than co-doping with $\mathrm{Na}^{+}$. The maximum luminescence intensity is achieved with the content of $3 \% \mathrm{Li}^{+}$doping. Fig. 6(b) illustrates the emission spectra of $\mathrm{CaSr}_{2-}$ ${ }_{2 x}\left(\mathrm{PO}_{4}\right)_{2}: x \mathrm{Dy}^{3+}, x \mathrm{Li}^{+}$and $\mathrm{CaSr}_{2-1.5 x}\left(\mathrm{PO}_{4}\right)_{2}: x \mathrm{Dy}^{3+}$ phosphors, showing the beneficial effect of $\mathrm{Li}^{+}$co-doping on the luminescence intensity of the samples. The phosphors need to produce ion defects to maintain the charge balance because the replacement of $\mathrm{Sr}^{2+}$ with $\mathrm{Dy}^{3+}$ is not equal. However, too many defects produce crystal lattice distortions that reduce the luminescence intensity. Instead, the introduction of $\mathrm{Li}^{+}$ ions means that the charge compensation takes place according to the following formula: $2 \mathrm{Sr}^{2+}=\mathrm{Dy}^{3+}+$ $\mathrm{Li}^{+}$. This limits the number of crystal defects and leads to the enhanced luminescence intensity. Moreover, $\mathrm{Li}^{+}$co-doping changes symmetry of the local coordination environment and the related crystal field strength. The reduced site symmetry may also lead to the enhanced luminescence intensity.

\subsection{Energy transfer mechanism}

The quenching of the emission intensity depends on the critical distance $R c$, which is the shortest average distance between the nearest dopant Dy ${ }^{3+}$ ions at a critical concentration $x_{C}$. The critical distance $R c$ is described by the following equation [36]:

$$
R c \approx 2\left[\frac{3 V}{4 \pi x_{c} N}\right]^{1 / 3}
$$

in which $V$ stands for the volume of the unit cell, $x_{C}$ is the critical concentration of activator ion (Dy ${ }^{3+}$ ) beyond the concentration quenching, and $\mathrm{N}$ represents the number of host cations in one unit cell. In our case, $\mathrm{N}=6 \mathrm{~V}$ was estimated to be $3744.14 \AA$, and $x_{c}$ is 0.06 according to the above discussions. According to the eq. (1), Rc was changed to $27.08 \AA\left(x_{c}=0.06\right)$. It is well-known that exchange interactions play a crucial role in the energy transfer mechanism when the critical distance between the sensitizer and the activator ions is less than $4 \AA$. With a much higher $R c$ value, the energy transfer mechanism is considered to be an electric multipolar interaction. Based on the Dexter's theory, if the 
energy transfer occurs by electric multipolar interactions, then the relationship between the luminescent intensity $(I)$ and the activator concentration $(x)$ can be expressed by the following equation [37]:

$$
\frac{1}{x}=\mathrm{K}\left[1+\beta(\mathrm{x})^{\frac{\theta}{3}}\right]^{-1}
$$

where $x$ is the activator concentration, $K$ and $\beta$ are constants for each interaction at the same excitation. $\theta$ is a multipolar interaction constant equal to $3,6,8$ or 10 , corresponding to the nearest-neighbor ions, i.e., dipole-dipole $(d-d)$, dipole-quadrupole $(d-q)$ and quadrupole-quadrupole $(q-q)$ interactions, respectively. We chose the $\mathrm{CaSr}_{2-2 x}\left(\mathrm{PO}_{4}\right)_{2}: x \mathrm{Xy}^{3+}{ }_{,}, x \mathrm{Li}^{+}(x=0.06,0.12,0.18,0.24,0.27$ and 0.3$)$ samples for the constant emission intensity measurements at $578 \mathrm{~nm}$ exceeding the quenching concentration. The relation of $\log (\mathrm{I} / x)$ vs. $\log (x)$ for the $\mathrm{CaSr}_{2-2 x}\left(\mathrm{PO}_{4}\right)_{2}: x \mathrm{Dy}^{3+}{ }_{,}, \mathrm{Li}^{+}(x=0.06,0.12,0.18,0.24,0.27$ and 0.3$)$ peaks at 486 and $578 \mathrm{~nm}$ was plotted and depicted in Fig. 7. All $q$ values are close to 6 , hence we can conclude that the quenching mechanism between $\mathrm{Dy}^{3+}$ ions in the $\mathrm{CaSr}_{2}\left(\mathrm{PO}_{4}\right)_{2}$ samples conforms to the dipole-dipole $(d-d)$ interactions.

\subsection{Temperature-dependent luminescent properties}

It is well-known that the luminescence intensity for most phosphors decreases if the operating temperature exceeds a certain value (thermal quenching). [38] Thus, the thermal stability of the phosphor is a key issue for high-power $w$-LEDs. One of the key requirements for a good phosphor is to maintain the performance at the operating temperature of the device. Usually, the luminescence intensity of the phosphors at $423 \mathrm{~K}$ with respect to that at room temperature is used to assess the thermal stability. The reason for this has been reported as an increase in the non-radiative transition probability in the configurational coordinated diagram. [39] Fig. 8 shows the temperature dependent emission spectra of the $\mathrm{CaSr}_{1.88}\left(\mathrm{PO}_{4}\right)_{2}: 0.06 \mathrm{Dy}^{3+}, 0.06 \mathrm{Li}^{+}$phosphor from 298 to $523 \mathrm{~K}$, at $351 \mathrm{~nm}$ excitation; the inset shows the relative emission intensities at 486 and $578 \mathrm{~nm}$ as a function of temperature. The shape of the emission bands remains unchanged with increasing temperature (Fig. 8), suggesting that the phosphor has excellent color stability, which is crucial in LEDs or high temperature LEDs. Upon heating the phosphor samples in the temperature range from $298 \mathrm{~K}$ to $523 \mathrm{~K}$, the emission intensity decreased slightly, since the probability of nonradiation is increased and luminescent $c$ enter is released through the crossing point between the excitation state and the ground state, causing the luminescence quenching. [40] Besides, Fig. 9 illustrated the PL intensity of $\mathrm{CaSr}_{1.88}\left(\mathrm{PO}_{4}\right)_{2}: 0.06 \mathrm{Dy}^{3+}, 0.06 \mathrm{Li}^{+}$phosphor with respect

to time, monitored under $351 \mathrm{~nm}$ excitation continuously for $60 \mathrm{~min}$ at (a) $100^{\circ} \mathrm{C}$ and (b) $150^{\circ} \mathrm{C}$ for $30 \mathrm{~min}$ at each temperature with a time interval of $5 \mathrm{~min}$, and the emission profile of phosphor maintained at $100^{\circ} \mathrm{C}$ and $150^{\circ} \mathrm{C}$ continuously for $30 \mathrm{~min}$ at each temperature showed that the emission intensity are very stable and remain unchanged, as well as without variation of the emission wavelength. In addition, the emission intensities of $\mathrm{CaSr}_{1.88}\left(\mathrm{PO}_{4}\right)_{2}: 0.06 \mathrm{Dy}^{3+}, 0.06 \mathrm{Li}^{+}$maintains $77 \%$ of the initial emission intensity corresponding to a temperature of $423 \mathrm{~K}$, revealing that the $\mathrm{CaSr}_{1.88}\left(\mathrm{PO}_{4}\right)_{2}: 0.06 \mathrm{Dy}^{3+}, 0.06 \mathrm{Li}^{+}$ 
phosphors have good thermal stability, which confirms the stable chromaticity coordinates of $\mathrm{CaSr}_{1.88}\left(\mathrm{PO}_{4}\right)_{2}: 0.06 \mathrm{Dy}^{3+}, 0.06 \mathrm{Li}^{+}$phosphors.

\subsection{Luminescence decay curves and chromaticity coordinates}

Fig. 10 shows the decay curves of $\mathrm{Dy}^{3+}$ emission for $\mathrm{CaSr}_{2-2 x}\left(\mathrm{PO}_{4}\right)_{2}: x \mathrm{Dy}^{3+}, x \mathrm{Li}^{+}(x=0.03,0.09,0.15$ and 0.18 ) samples excited at $351 \mathrm{~nm}$ and monitored at $578 \mathrm{~nm}$. All decay curves can be well fitted to a biexponential decay equation as follows:

$I=A_{1} \exp \left(-x / \tau_{1}\right)+A_{2} \exp \left(-x / \tau_{2}\right)$

where $\mathrm{I}$ is the luminescence intensity at time $\mathrm{t}, \mathrm{A} 1$ and $\mathrm{A} 2$ are amplitudes, and $\mathrm{t} 1$ and $\mathrm{t} 2$ are the luminescence lifetimes. The average emission lifetimes $\tau$ were calculated by following formula:

$$
\tau=\frac{A 1 * \tau 1^{2}+\mathrm{A} 2 * \tau 2^{2}}{A 1 * \tau 1+\mathrm{A} 2 * \tau 2}
$$

The calculated average emission lifetimes decrease with increasing $D y^{3+}$ concentration, i.e. 0.74, 0.47, 0.22 and $0.11 \mathrm{~ms}$ for the $\mathrm{CaSr}_{2-2 x}\left(\mathrm{PO}_{4}\right)_{2}: x \mathrm{Dy}^{3+}{ }^{+}, \mathrm{Li}^{+}$samples with $x=0.03,0.09,0.15$ and 0.18 , respectively. This is due to the decreasing distance between $\mathrm{Dy}^{3+}-\mathrm{Dy}^{3+}$ ions, resulting in the observed concentration quenching phenomenon (enhanced cross-relaxations processes), as well as enhanced probability of energy transfer to the luminescence killer sites. Thereby, the luminescence lifetimes of $\mathrm{Dy}^{3+}$ ions are shortened due to the favorable nonradiative energy transfer processes when the Dy ${ }^{3+}$ concentration increases. The observed bi-exponential character of the decay curves could be because of the non-equal occupation of the cation sites by the emitting activator $\mathrm{Dy}^{3+}$ that has a concentrationdependent preferential occupation in one of the sites as well.

The Commission International de l'Eclairage (CIE) chromaticity coordinates for the representative sample $\left(\mathrm{Ca}_{2} \mathrm{Sr}_{1.88}\left(\mathrm{PO}_{4}\right)_{2}: 0.06 \mathrm{Dy}^{3+}, 0.06 \mathrm{Li}^{+}\right)$were calculated based on the corresponding emission spectra, and the results are shown in Fig. 11(a). It can be seen that the coordinates $(x=0.3450, y=0.3787)$ are located in the near-white region. In addition, we also calculated the CIE chromaticity coordinates of $\mathrm{Ca}_{2} \mathrm{Sr}_{1.88}\left(\mathrm{PO}_{4}\right)_{2}: 0.06 \mathrm{Dy}^{3+}{ }^{+}, 0.06 \mathrm{Li}^{+}$at different temperature values (Table 1 ), and we found that with the temperature rising the phosphor exhibits almost no change in the color of emission, which is showed in Fig. 11(b). Thus, the $\mathrm{CaSr}_{2-2 x}\left(\mathrm{PO}_{4}\right)_{2}: \mathrm{XDy}^{3+}, \mathrm{xLi}^{+}$material can be potentially used as a white phosphor for $w$-LEDs in solid-state lighting applications.

\section{Conclusions}

In summary, a series of $\mathrm{CaSr}_{2-2 x}\left(\mathrm{PO}_{4}\right)_{2}: x \mathrm{Dy}^{3+}{ }^{+}, x \mathrm{Li}^{+}, \mathrm{CaSr}_{2-2 x}\left(\mathrm{PO}_{4}\right)_{2}: x \mathrm{Dy}^{3+}{ }^{+}, x \mathrm{Na}^{+}$and $\mathrm{CaSr}_{2-1.5 x}\left(\mathrm{PO}_{4}\right)_{2}: \mathrm{xDy}^{3+}$ phosphors were prepared by a conventional solid-state reaction. The phase structure, luminescence properties, thermal quenching and emission decay curves were investigated. Under the excitation of 351 
$\mathrm{nm}$, the $\mathrm{CaSr}_{2-2 x}\left(\mathrm{PO}_{4}\right)_{2}: x \mathrm{Dy}^{3+}{ }^{+}, x \mathrm{Li}^{+}$phosphors showed two emission bands centered at 486 and $578 \mathrm{~nm}$, characteristic of $\mathrm{Dy}^{3+}$. The excitation spectra showed narrow excitation bands from 250 to $550 \mathrm{~nm}$ with a maximum at $403 \mathrm{~nm}$. This means that the phosphor can be effectively excited by UV chips for potential applications in $w$-LEDs. The optimum dopant concentration of $\mathrm{Dy}^{3+}$ ions is $0.06 \mathrm{~mol}$.\%. Furthermore, the quenching mechanism between the $\mathrm{Dy}^{3+}$ ions was recognized as dipole-dipole $(d-d)$ interactions. The dependence of the emission spectra on temperature indicated that the phosphor has a good thermal stability in both emission color and intensity. The CIE chromaticity coordinates of the selected $\mathrm{Ca}_{2} \mathrm{Sr}_{1.88}\left(\mathrm{PO}_{4}\right)_{2}: 0.06 \mathrm{Dy}^{3+}, 0.06 \mathrm{Li}^{+}$sample were calculated $(x=0.3450, y=0.3787)$, and they are located in the white-light region. These results indicate that $\mathrm{CaSr}_{2-2 x}\left(\mathrm{PO}_{4}\right)_{2}: x \mathrm{Dy}^{3+}, x \mathrm{Li}^{+}$phosphors have a good potential for their use as white-emitting luminophores for the phosphor-converted $w$-LEDs. Thus, the results of this work indicate the potential applications of these effective phosphors in white light-emitting diodes, excited with a near-UV chip.

\section{Declarations}

\section{Conflicts of interest}

There are no conflicts to declare.

\section{Acknowledgements}

The present work is supported by the National Natural Science Foundation of China (Grant No. 41802040) and the Fundamental Research Funds for China University of Geosciences, Beijing (Grant No. 2652019080).

\section{References}

1. M.M. Shang, G.G. Li, D.L. Geng, D.M. Yang, X.J. Kang, Y. Zhang, H.Z. Lian, J. Lin, Blue Emitting $\mathrm{Ca}_{8} \mathrm{La}_{2}\left(\mathrm{PO}_{4}\right)_{6} \mathrm{O}_{2}: \mathrm{Ce}^{3+} / \mathrm{Eu}^{2+}$ Phosphors with High Color Purity and Brightness for White LED: SoftChemical Synthesis, Luminescence, and Energy Transfer Properties, J. Phys. Chem. 116 (2012) 10222-10231.

2. H. Guo, B. Devakumar, R. Vijayakumar, P. Du, X.Y. Huang, A novel $\mathrm{Sm}^{3+}$ singly doped $\mathrm{LiCa}_{3} \mathrm{ZnV}_{3} \mathrm{O}_{12}$ phosphor: a potential luminescent material for multifunctional applications, RSC Adv. 8 (2018) 33403-33413.

3. L. Li, X.H. Tang, Z.Q. Jiang, X.J. Zhou, S. Jiang, X.B. Luo, G.T. Xiang, K.N. Zhou, $\mathrm{NaBaLa}_{2}\left(\mathrm{PO}_{4}\right)_{3}$ : A novel host lattice for $\mathrm{Sm}^{3+}$-doped phosphor materials emitting reddish-orange light, J. Alloys Compd. 701 (2017) 515-523.

4. K. Jayanthi, S.V. Manorama, Lumino-magnetic YAG:Ce nanophosphors: novel synthesis routes for efficient luminescence and magnetic properties, J. Mater. Chem. C 2 (2014) 10322-10330. 
5. Y.L. Zhu, Y.J. Liang, H.R. Li, J.H. Chen, W. Lei, A strategy for realizing tunable luminescence and fullcolor emission in $\mathrm{Sr}_{3} \mathrm{Gd}_{2}\left(\mathrm{Si}_{3} \mathrm{O}_{9}\right)_{2}$ :Eu phosphors by introducing dual functional $\mathrm{Mn}^{2+}$, Inorg. Chem. Front. 5 (2018) 2527-2539.

6. K.N. Shinde, A. Hakeem, S.J. Dhoble, K. Park, Photoluminescence properties of $\left(\mathrm{Sr}_{1-\mathrm{x}} \mathrm{Ca}_{\mathrm{x}}\right)_{1-\mathrm{y}} \mathrm{ZrO}_{3}: \mathrm{yEu}^{3+}$ phosphors for near-ultraviolet excited LEDs, Ceram. Int. 40 (2014) 551-555.

7. Q. Dai, M.E. Foley, C.J. Breshike, A. Lita, G.F. Strouse, Ligand-passivated Eu: $\mathrm{Y}_{2} \mathrm{O}_{3}$ nanocrystals as a phosphor for white light emitting diodes, J. Am. Chem. Soc. 133 (2011) 15475-15486.

8. A.N. Yerpude, S.J. Dhoble, Luminescence in trivalent rare earth activated $\mathrm{Sr}_{4} \mathrm{Al}_{2} \mathrm{O}_{7}$ phosphor, Optik 124 (2013) 3567-3570.

9. S. Li, D. Tang, Z. Tian, X. Liu, T. Takeda, N. Hirosaki, F. Xu, Z. Huang, R.-J. Xie, New insights into the microstructure of translucent $\mathrm{CaAlSiN}_{3}: \mathrm{Eu}^{2+}$ phosphor ceramics for solid-state laser lighting, $\mathrm{J}$. Mater. Chem. C 5 (2017) 1042-1051.

10. K.Y. Kim, S.J. Yoon, K. Park, Synthesis and photoluminescence properties of redemitting $\mathrm{Ca}_{3-}$ $3 \times / 2\left(\mathrm{VO}_{4}\right)_{2}: \mathrm{xEu}^{3+}$ phosphors, J. Lumin. 160 (2015) 78-84.

11. W. Sun, Y. Jia, R. Pang, H. Li, T. Ma, D. Li, J. Fu, S. Zhang, L. Jiang, C. Li, $\operatorname{Sr}_{9} \mathrm{Mg}_{1.5}\left(\mathrm{PO}_{4}\right)_{7}$ :Eu ${ }^{2+}$ : a novel broadband orange-yellow-emitting phosphor for blue light-excited warm white LEDs, ACS Appl. Mater. Interfaces 7 (2015) 25219-25226.

12. Z. Wang, S. Lou, P. Li, Z. Lian, Single-phase tunable white-light-emitting $\mathrm{Sr}_{3} \mathrm{La}\left(\mathrm{PO}_{4}\right)_{3}: \mathrm{Eu}^{2+}, \mathrm{Mn}^{2+}$ phosphor for white LEDs, Appl. Opt. 56 (2017) 1167-1172.

13. J.S. Kim, P.E. Jeon, J.C. Choi, H.L. Park, S.I. Mho, G.C. Kim, Warm-white-light emitting diode utilizing a single-phase full-color $\mathrm{Ba}_{3} \mathrm{MgSi}_{2} \mathrm{O}_{8}: \mathrm{Eu}^{2+}, \mathrm{Mn}^{2+}$ phosphor, Appl. Phys. Lett. 84 (2004) 2931-2933.

14. S. Zhang, Y. Li, Y. Lv, L. Fan, Y. Hu, M. He, A full-color emitting phosphor $\mathrm{Ca}{ }_{9} \mathrm{Ce}\left(\mathrm{PO}_{4}\right)_{7}: \mathrm{Mn}^{2+}, \mathrm{Tb}^{3+}$ : efficient energy transfer, stable thermal stability and high quantum efficiency, Chem. Eng. J. 322 (2017) 314-327.

15. B. Han, J. Zhang, B. Liu, J. Zhang, H. Shi, $\mathrm{Ce}^{3+}-\mathrm{Tb}^{3+}$ energy transfer induced emission-tunable properties of $\mathrm{Ba}_{3} \mathrm{La}\left(\mathrm{PO}_{4}\right)_{3}: \mathrm{Ce}^{3+}, \mathrm{Tb}^{3+}$ phosphors, Mater. Lett. 181 (2016) 305-308.

16. J.C. Zhang, Y.-Z. Long, H.-D. Zhang, B. Sun, W.-P. Han, X.-Y. Sun, $\mathrm{Eu}^{2+} / \mathrm{Eu}^{3+}$ - emission-ratio-tunable $\mathrm{CaZr}\left(\mathrm{PO}_{4}\right)_{2}$ :Eu phosphors synthesized in air atmosphere for potential white light-emitting deep UV LEDs, J. Mater. Chem. C 2 (2014) 312-318.

17. Y. Wang, W. Zhang, J. Li, J. Long, Effect of $\mathrm{MoO}_{4}$ 2- partial substitution on optical enhancement of $\mathrm{LaNa}\left(\mathrm{MoO}_{4}\right)_{2}: \mathrm{Dy}^{3+}$ phosphors for white light emitting diodes, Mater. Sci. Semicond. Proc. 41 (2016) 277-281.

18. S. Dutta, S. Som, S.K. Sharma, Luminescence and photometric characterization of $\mathrm{K}^{+}$compensated $\mathrm{CaMoO}_{4}: \mathrm{Dy}^{3+}$ nanophosphors, Dalton Trans. 42 (2013) 9654-9661. 
19. Z. Zhang, C. Han, W. Shi, Y. Kang, Y. Wang, W. Zhang, D. Wang, Enhanced novel white emission in $\mathrm{Ca}_{3}\left(\mathrm{PO}_{4}\right)_{2}:$ Dy ${ }^{3+}$ single-phase full-color phosphor by charge compensation, J. Mater. Sci. -Mater. Electron. 26 (2015) 1923-1931.

20. Y. Liu, B. Lei, C. Shi, Luminescent properties of a white afterglow phosphor $\mathrm{CdSiO}_{3}: \mathrm{Dy}^{3+}$, Chem. Mater. 17 (2005) 2108-2113.

21. W. Zhang, Y. Lu, H. Du, J. Lin, J. Long, Sol-gel-nitridation preparation and photoluminescence properties of $\mathrm{Dy}^{3+}$-doped $\mathrm{M}_{2} \mathrm{Si}_{5} \mathrm{~N}_{8}(\mathrm{M}=\mathrm{Ca}, \mathrm{Sr}, \mathrm{Ba})$ phosphors for white light emitting diodes, Ceram. Int. 43 (2017) 1080-1085.

22. I.M. Nagpure, S. Saha, S.J. Dhoble, Photoluminescence and thermoluminescence characterization of $\mathrm{Eu}^{3+}$ - and Dy ${ }^{3+}$-activated $\mathrm{Ca}_{3}\left(\mathrm{PO}_{4}\right)_{2}$ phosphor, J. Lumin. 129 (2009) 898-905.

23. G.B. Nair, S.J. Dhoble, White light emitting $\mathrm{MZr}_{4}\left(\mathrm{PO}_{4}\right)_{6}: \mathrm{Dy}^{3+}(\mathrm{M}=\mathrm{Ca}, \mathrm{Sr}, \mathrm{Ba})$ phosphors for WLEDs, J. Fluoresc. 27 (2017) 575-585.

24. P. Kumari, J. Manam, Effects of morphology on the structural and photoluminescence properties of co-precipitation derived $\mathrm{GdVO}_{4}: \mathrm{Dy}^{3+}$, Chem. Phys. Lett. 662 (2016) 56-61.

25. B. Zhai, L. Yang, Q. Ma, X. Liu, Y.M. Huang, Mechanism of the prolongation of the green afterglow of $\mathrm{SrAl}_{2} \mathrm{O}_{4}: \mathrm{Dy}^{3+}$ caused by the use of $\mathrm{H}_{3} \mathrm{BO}_{3}$ flux, J. Lumin. 181 (2017) 78-87.

26. S.K. Gupta, V. Grover, R. Shukla, K. Srinivasu, V. Natarajan, A.K. Tyagi, Exploring pure and RE co-doped $\left(\mathrm{Eu}^{3+}, \mathrm{Tb}^{3+}\right.$ and $\left.\mathrm{Dy}^{3+}\right)$ gadolinium scandate: luminescence behaviour and dynamics of energy transfer, Chem. Eng. J. 283 (2016) 114-126.

27. S. Hu, X. Qin, G. Zhou, X. Liu, C. Lu, Z. Xu, S. Wang, Effect of doping concentration on particle growth and luminescence properties of monodispersed $\mathrm{Dy}^{3+}: \mathrm{Y}_{2} \mathrm{O}_{3}$, J. Alloy. Compd. 664 (2016) 304-310.

28. X. Wang, F. Du, D. Wei, Y. Huang, H.J. Seo, The blue-emitting phosphor of $\mathrm{Eu}^{2+}$ - doped $\mathrm{Ca}_{2} \mathrm{Sr}\left(\mathrm{PO}_{4}\right)_{2}$, J. Electrochem. Soc. 158 (2011) J264-J268.

29. F. Chen, X. Yuan, F. Zhang, S. Wang, Photoluminescence properties of $\mathrm{Sr}_{3}\left(\mathrm{PO}_{4}\right)_{2}: \mathrm{Eu}^{2+}, \mathrm{Dy}^{3+}$ doubleemitting blue phosphor for white LEDs, Opt. Mater. 37 (2014) 65-69.

30. Y. Chen, Q. Guo, L. Liao, M. He, T. Zhou, L. Mei, M. Runowski, and B. Ma, Preparation, crystal structure and luminescence properties of a novel single-phase red emitting phosphor $\mathrm{CaSr}_{2}\left(\mathrm{PO}_{4}\right)_{2}: \mathrm{Sm}^{3+}, \mathrm{Li}^{+}$, RSC Adv. 9 (2019), 9, 4834-4842.

31. S. Dai, W. Zhang, D. Zhou, G. Yan, and S. Liu, Effect of $A^{+}(A=L i, N a$ and K) co-doping on the luminescence enhancement of $\mathrm{CaSr}_{2}\left(\mathrm{PO}_{4}\right)_{2}$ :Dy ${ }^{3+}$ phosphors for white light-emitting diodes, Ceram. Int. 43 (2017) 15493-15499.

32. H. Ji, Z. Huang, Z. Xia, M.S. Molokeev, V.V. Atuchin, M. Fang, S. Huang, New yellow-emitting whitlockite-type structure $\mathrm{Sr}_{1.75} \mathrm{Ca}_{1.25}\left(\mathrm{PO}_{4}\right)_{2}$ : $\mathrm{Eu}^{2+}$ phosphor for near-UV pumped white light-emitting devices, Inorg. Chem. 53 (2014) 5129-5135. 
33. W. Tang, Z. Zhang, Realization of color tuning via solid-solution and energy transfer in $\mathrm{Ca}_{3-\mathrm{x}} \mathrm{Sr}_{\mathrm{x}}\left(\mathrm{PO}_{4}\right)_{2}: \mathrm{Eu}^{2+}, \mathrm{Mn}^{2+}$ phosphors, J. Mater. Chem. C.3 (2015) 5339-5346.

34. I.M. Nagpure, S.S. Pitale, E. Coetsee, O.M. Ntwaeaborwa, J.J. Terblans, H.C. Swart, Low voltage electron induced cathodoluminescence degradation and surface characterization of $\mathrm{Sr}_{3}\left(\mathrm{PO}_{4}\right)_{2}: \mathrm{Tb}$ phosphor, Appl. Surf. Sci. 257 (2011) 10147-10155.

35. Y. Lu, X. Tang, L. Yan, K. Li, X. Liu, M. Shang, C. Li, J. Lin, Synthesis and luminescent properties of $\mathrm{GdNbO}_{4}: \mathrm{RE}^{3+}(\mathrm{RE}=\mathrm{Tm}, \mathrm{Dy})$ nanocrystalline phosphors via the sol-gel process, J. Phys. Chem. C 117 (2013) 21972-21980.

36. Y. Zeng, K. Qiu, Z. Yang, Y. Bu, W. Zhang, J. Li, Enhanced red emission of $\mathrm{NaSrVO}_{4}: \mathrm{Eu}^{3+}$ phosphor via $\mathrm{Bi}^{3+}$ co-doping for the application to white LEDs, Ceram. Int. 43 (2017) 830-834.

37. L. G. Van Uitert, Characterization of Energy Transfer Interactions between Rare Earth lons, J. Electro. Chem. Soc. 114 (1967) 1048-1053.

38. H.Ye, M. Y. He, T. S. Zhou, Q. F. Guo, J. L. Zhang, L. B. Liao, L. F. Mei, H. K. Liu, M. Runowski, A novel reddish-orange fluorapatite phosphor, $\mathrm{La}_{6-\mathrm{x}} \mathrm{Ba}_{4}\left(\mathrm{SiO}_{4}\right)_{6} \mathrm{~F}_{2}: x \mathrm{Sm}^{3+}$ - Structure, luminescence and energy transfer properties, J. Alloys Compd. 757 (2018) 79-86.

39. S. Liu, Z.J. Wang, Q. Bao, X. Li, Y. Chen, Z.P. Wang, L. Guan, Abnormal thermal quenching and blueshift of $\mathrm{Zn}_{3}\left(\mathrm{BO}_{3}\right)\left(\mathrm{PO}_{4}\right)$ :Inducing host defect by doping $\mathrm{Mn}^{2+}$ and $\mathrm{Tb}^{3+}$, Dyes and Pigments, 165 (2019) 44-52.

40. J.J. Chen, Y. Zhao, Z.Y. Mao, D.J. Wang, L.J. Bie. Investigation of thermal quenching and abnormal thermal quenching in mixed valence Eu co-doped $\mathrm{LaAlO}_{3}$ phosphor, J Lumin, 186 (2017) 72-76.

\section{Tables}

Table 1 The CIE chromaticity coordinates of $\mathrm{Ca}_{2} \mathrm{Sr}_{1.88}\left(\mathrm{PO}_{4}\right)_{2}: 0.06 \mathrm{Dy}^{3+}, 0.06 \mathrm{Li}^{+}$at different temperature values. 


\begin{tabular}{|lll|}
\hline Temperature $(\mathrm{K})$ & $\mathrm{x}$ & $\mathrm{y}$ \\
\hline 298 & 0.3917 & 0.4101 \\
323 & 0.3795 & 0.3879 \\
\hline 348 & 0.3918 & 0.4099 \\
\hline 373 & 0.3905 & 0.4086 \\
\hline 398 & 0.3890 & 0.4067 \\
\hline 423 & 0.3876 & 0.4051 \\
\hline 448 & 0.3803 & 0.3925 \\
\hline 473 & 0.3840 & 0.4002 \\
\hline 498 & 0.3811 & 0.3967 \\
\hline 523 & 0.3786 & 0.3935 \\
\hline
\end{tabular}

Figures 


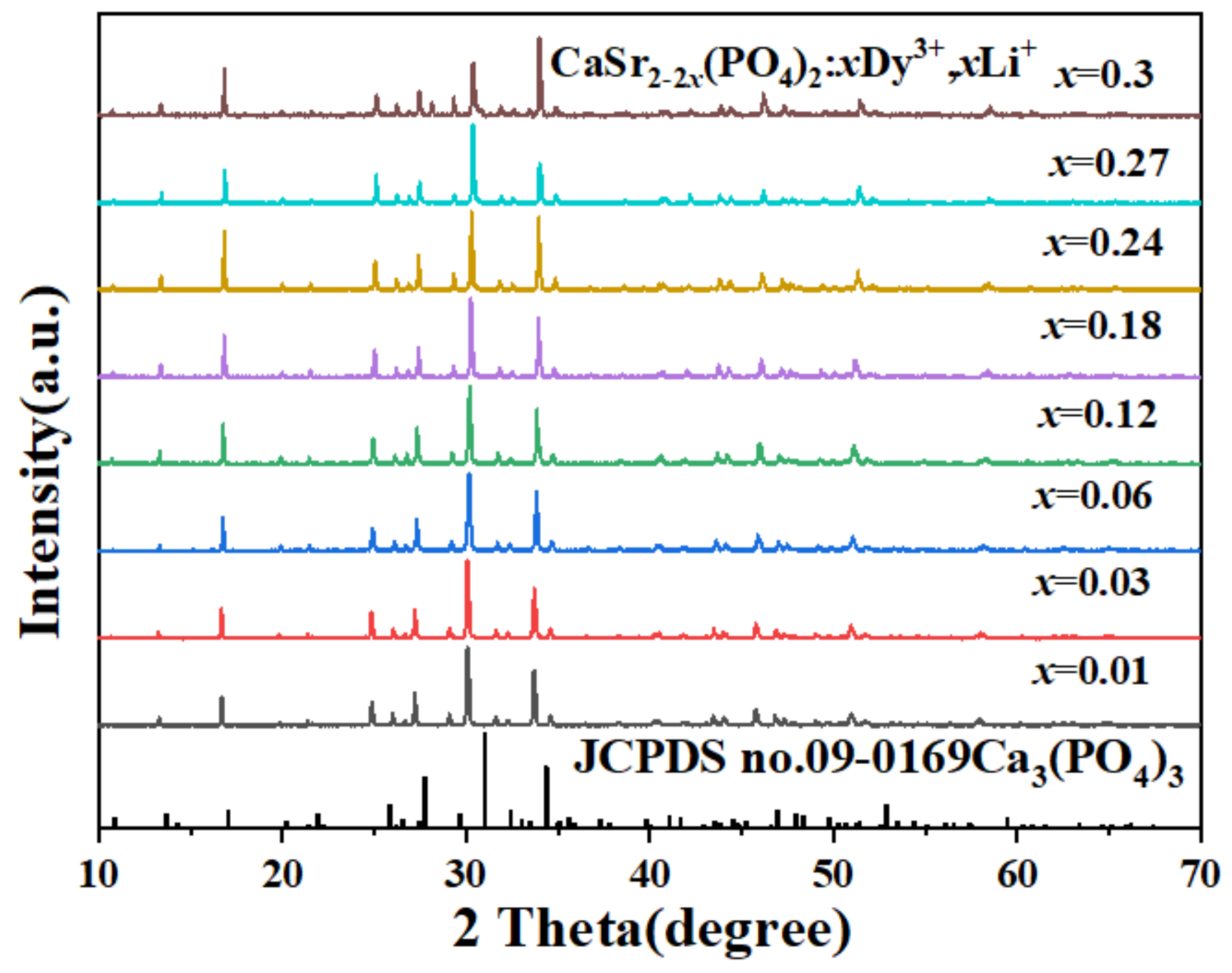

Figure 1

XRD patterns of the CaSr2-2x(PO4)2:xDy3+, $x$ Li+ phosphors $(x=0.01,0.03,0.06,0.12,0.18,0.24,0.27$ and 0.3 ) and the standard pattern of Ca3(PO4)2 (JCPDS no. 09-0169) is shown as a reference. 


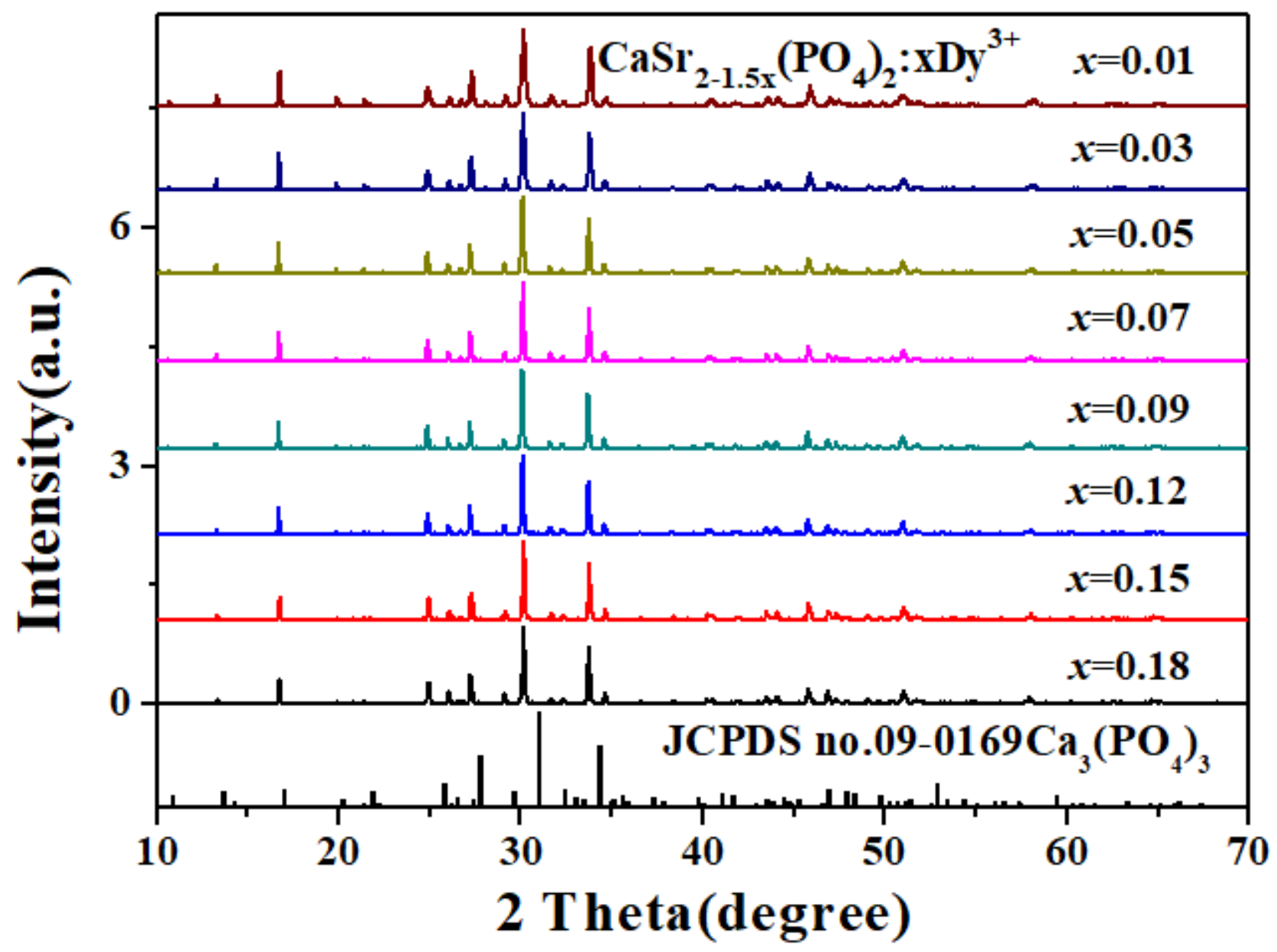

Figure 2

XRD patterns of the CaSr2-1.5x(P04)2:xDy3+ phosphors $(x=0.01,0.03,0.05,0.07,0.09,0.12,0.15$ and 0.18 ) and the standard pattern of $\mathrm{Ca} 3(\mathrm{PO} 4) 2$ (JCPDS no. 09-0169) is shown as a reference.

a)

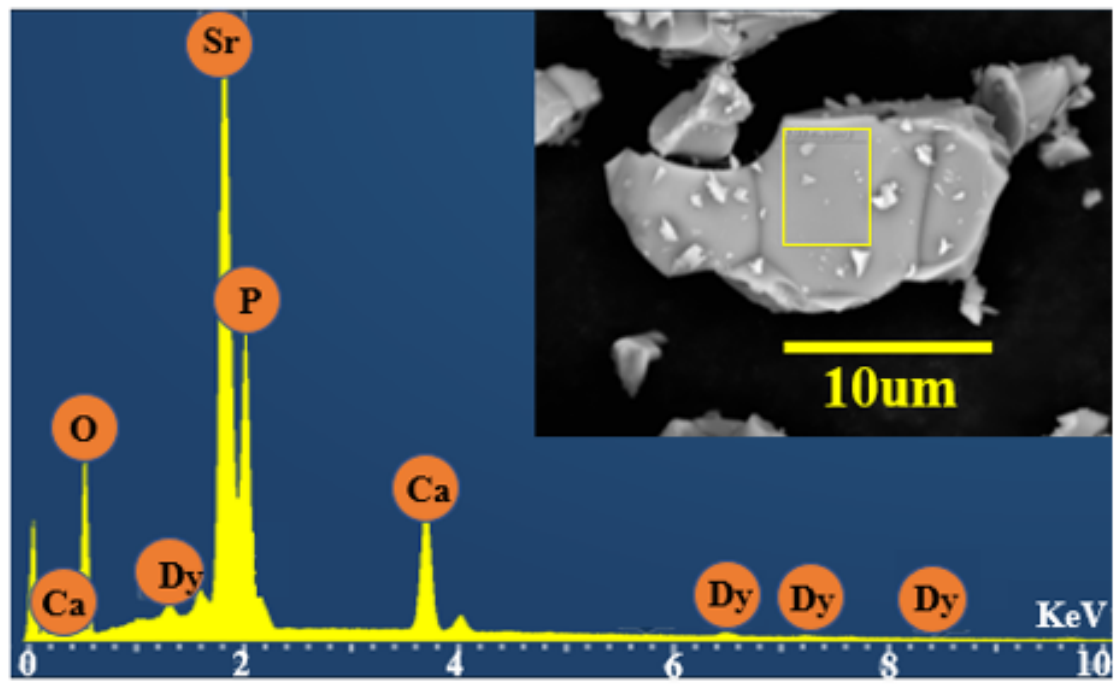

b)
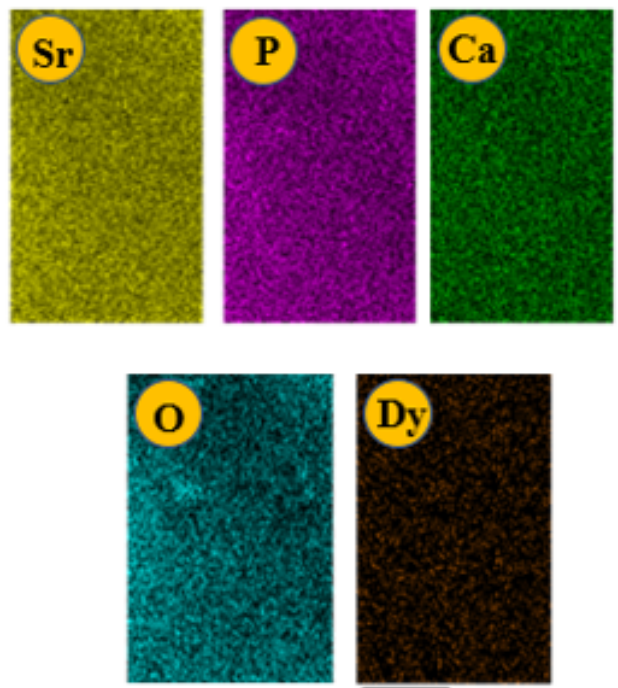

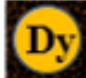

Figure 3 
(a) The elemental analysis result of the sample measured by the EDS method and the inset showing the SEM image of the CaSr1.88(PO4)2:0.06Dy3+,0.06 Li+ sample; (b) The elemental mapping of CaSr1.88(PO4)2:0.06Dy3+,0.06 Li+ phosphors.

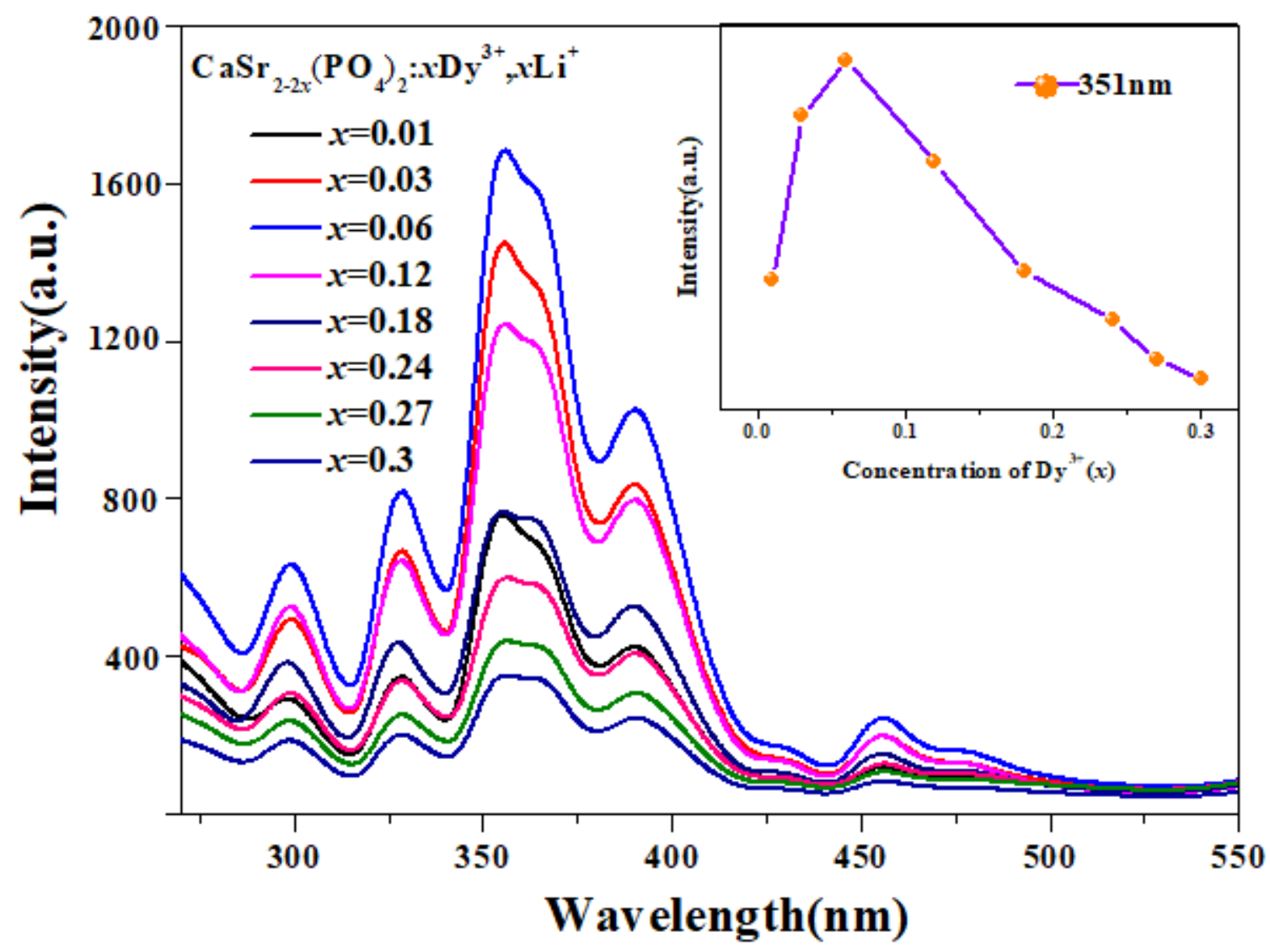

Figure 4

PLE spectra of the CaSr2-2x(PO4)2:xDy3+, $x \mathrm{Li}+(\mathrm{x}=0.01-0.3)$ phosphors, measured at room temperature; the inset shows the dependence of the excitation intensity at $351 \mathrm{~nm}$ on the Dy3+ doping concentration. 


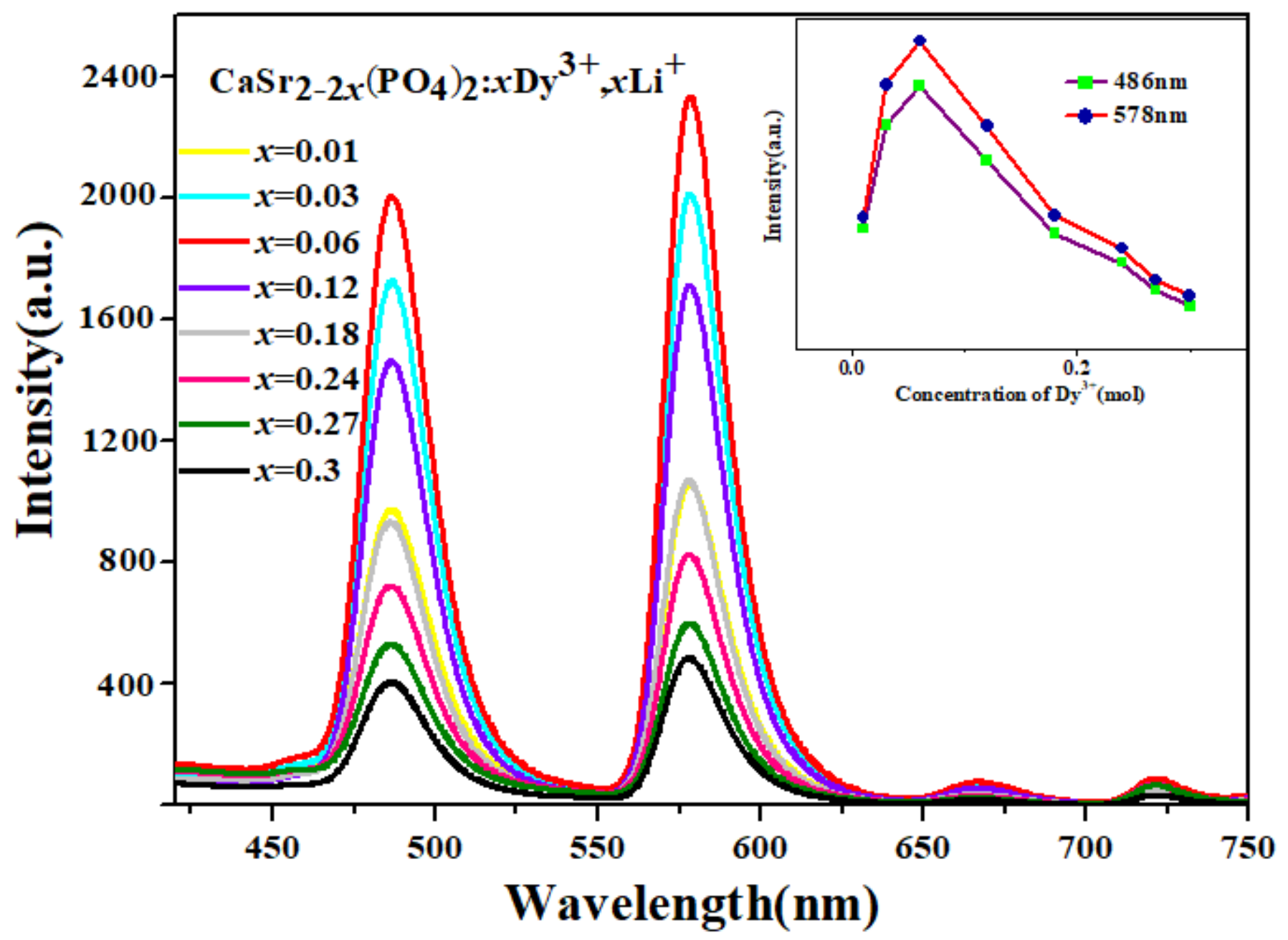

Figure 5

$\mathrm{PL}$ spectra of the CaSr2-2x(PO4)2:xDy3+,xLi+ $(x=0.01-0.3)$ phosphors, measured at room temperature with the excitation of $351 \mathrm{~nm}(6 \mathrm{H} 15 / 2$ to $6 \mathrm{P} 3 / 2)$; the inset shows the dependence of the emission intensity at 486 and $578 \mathrm{~nm}$ on the Dy3+ doping concentration. 

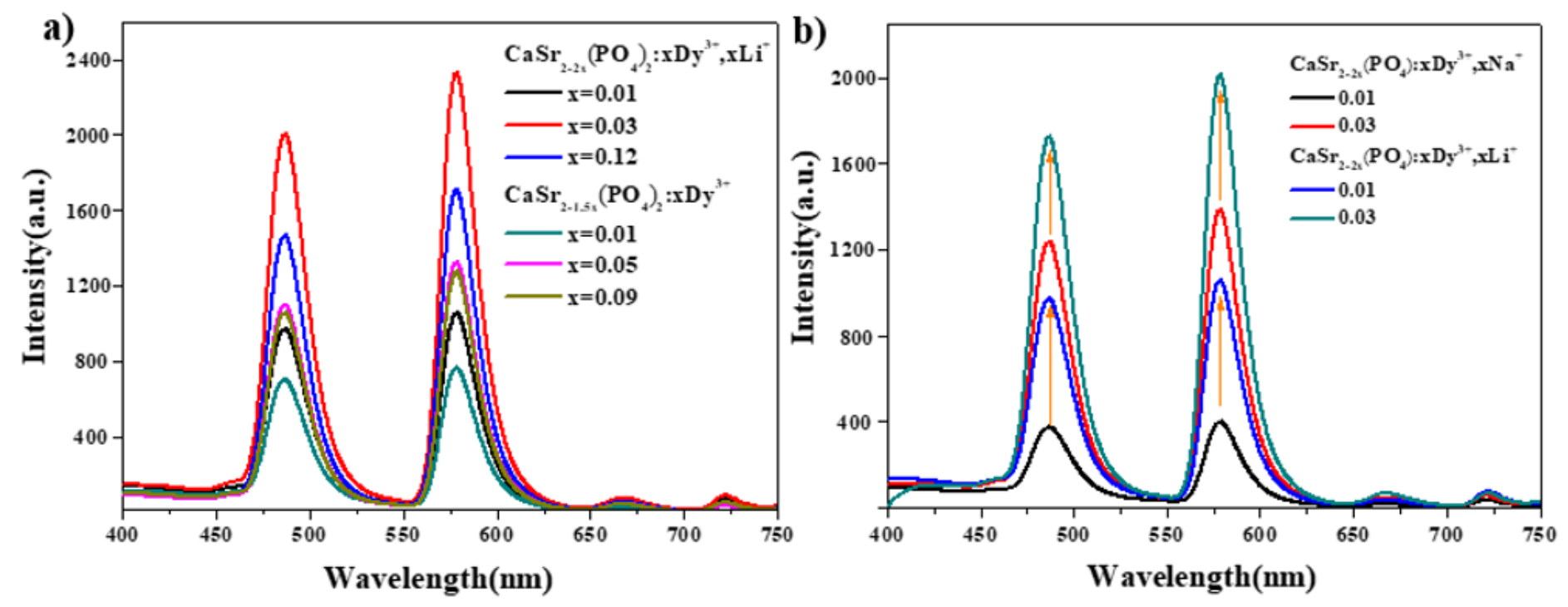

Figure 6

(a) Emission spectra of the CaSr2-2x(PO4)2:xDy3+, xLi+ ( $x=0.01,0.03$ and 0.12$)$ and CaSr21.5x(PO4)2:xDy3+ ( $\mathrm{x}=0.01,0.05$ and 0.9) phosphors; (b) Emission spectra of the CaSr22x(PO4)2:xDy3+,xLi+ ( $x=0.01$ and 0.03) and CaSr2-2x(PO4)2:xDy3+, xNa+ ( $x=0.01$ and 0.03) phosphors. 


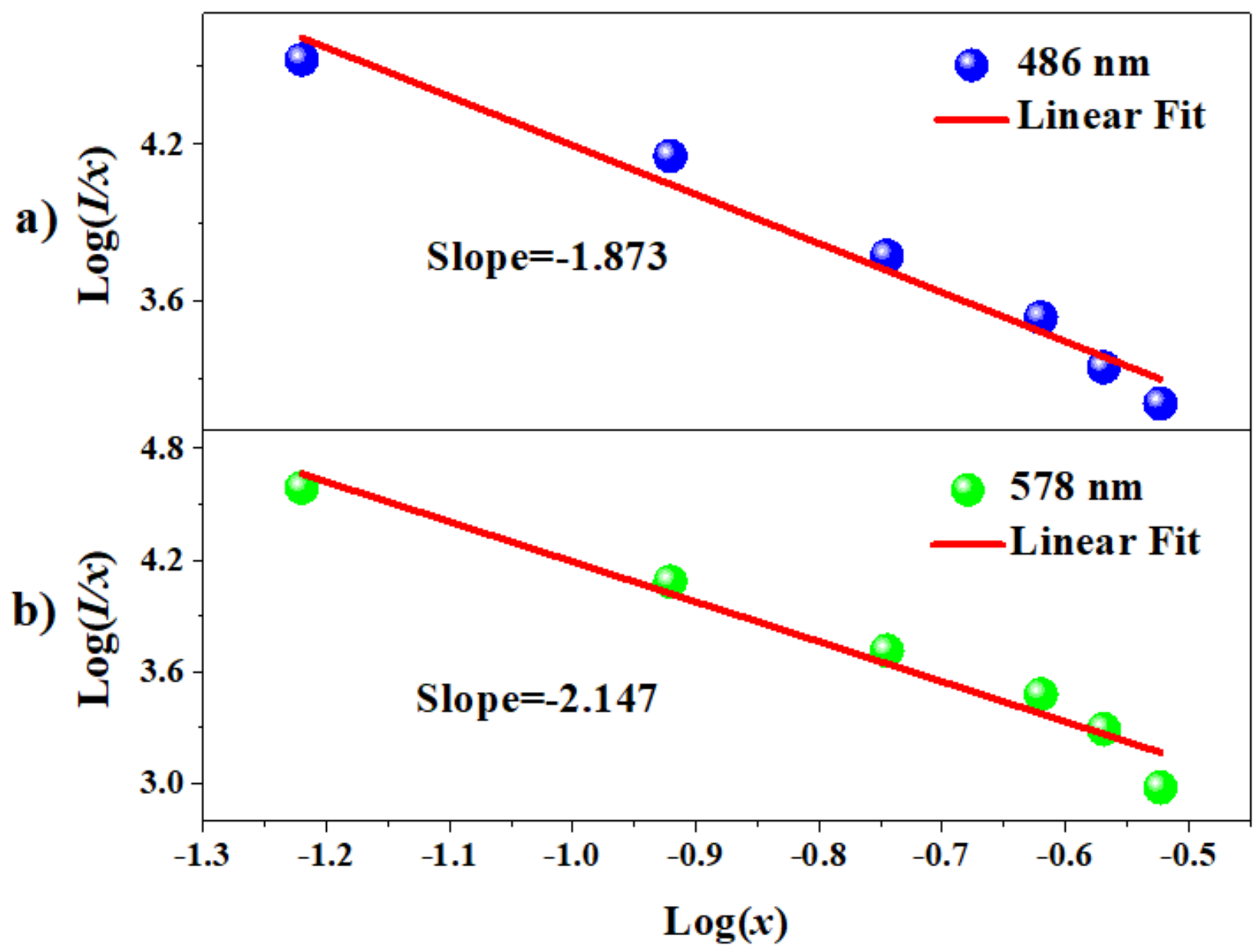

Figure 7

The relation of $\log (\mathrm{I} / \mathrm{x})$ vs. $\log (\mathrm{x})$ for the CaSr2-2x(PO4)2:xDy3+,xLi+ $(\mathrm{x}=0.06,0.12,0.18,0.24,0.27$ and 0.3 ) peaks at 486 and $578 \mathrm{~nm}$. 


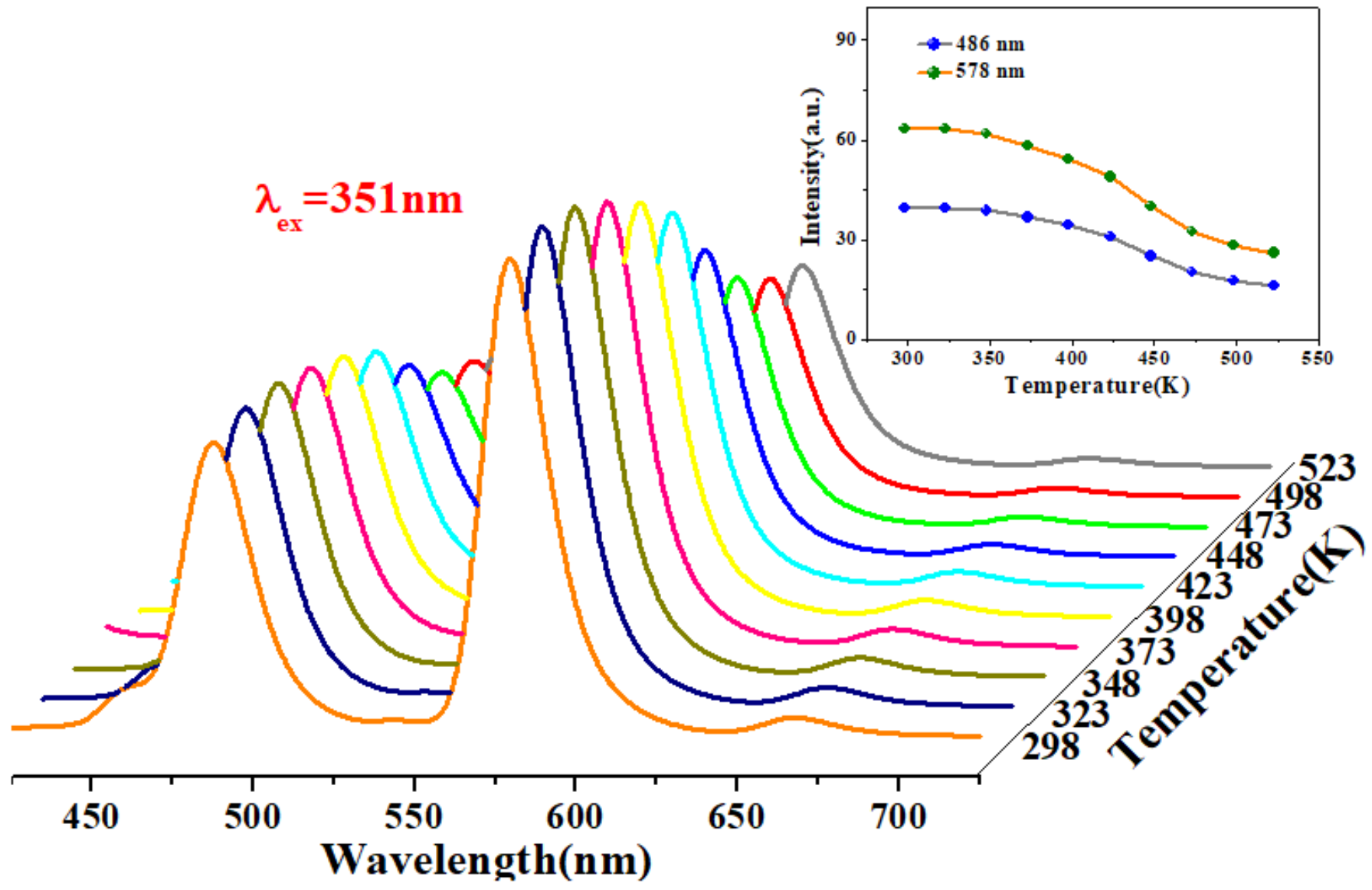

Figure 8

Temperature dependent emission spectra of the CaSr1.88(P04)2:0.06Dy3+,0.06 Li+ phosphor from 298 to $523 \mathrm{~K}$ with $351 \mathrm{~nm}$ excitation; the inset shows the relative emission intensities at 486 and $578 \mathrm{~nm}$ as a function of temperature.
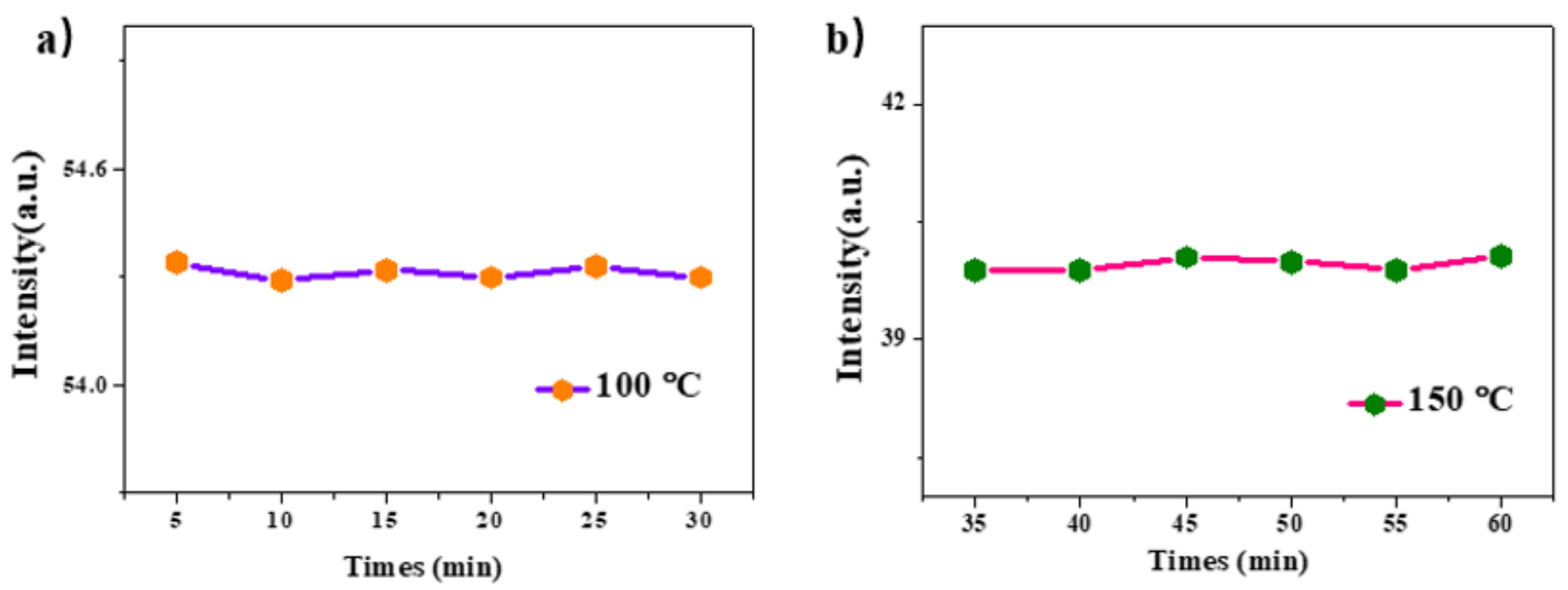

Figure 9 
The PL intensity of CaSr1.88(P04)2:0.06Dy3+,0.06 Li+ phosphor with respect to time, monitored under $351 \mathrm{~nm}$ excitation continuously for $60 \mathrm{~min}$ at (a) $100^{\circ} \mathrm{C}$ and (b) $150^{\circ} \mathrm{C}$ for $30 \mathrm{~min}$ at each temperature with a time interval of 5 min.

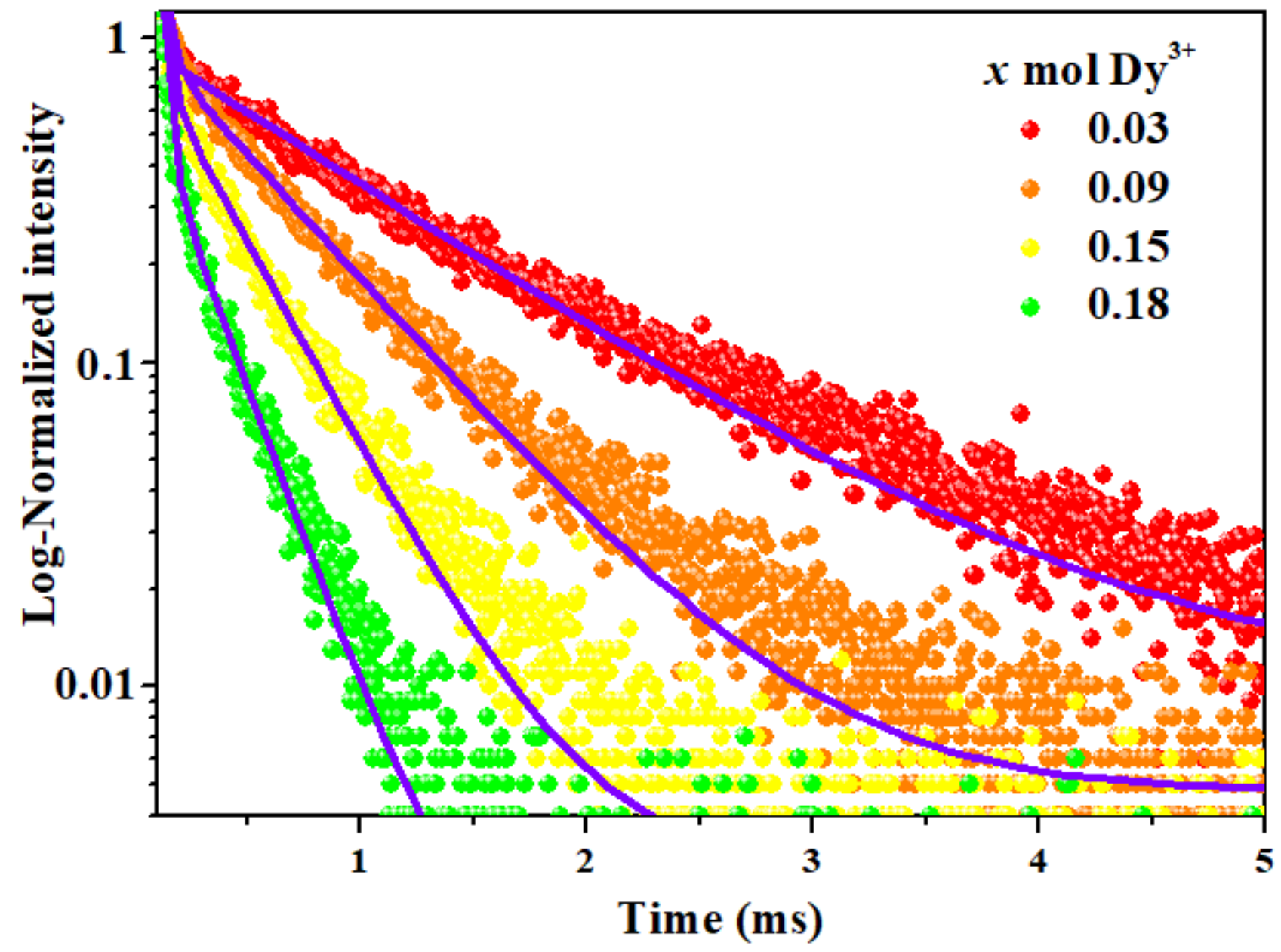

Figure 10

The decay curves of Dy3+ emission for CaSr2-2x(PO4)2: $x$ Dy3,$+ x \mathrm{Li}+(x=0.03,0.09,0.15$ and 0.18$)$ samples excited at $351 \mathrm{~nm}$ and monitored at $578 \mathrm{~nm}$. 
a)

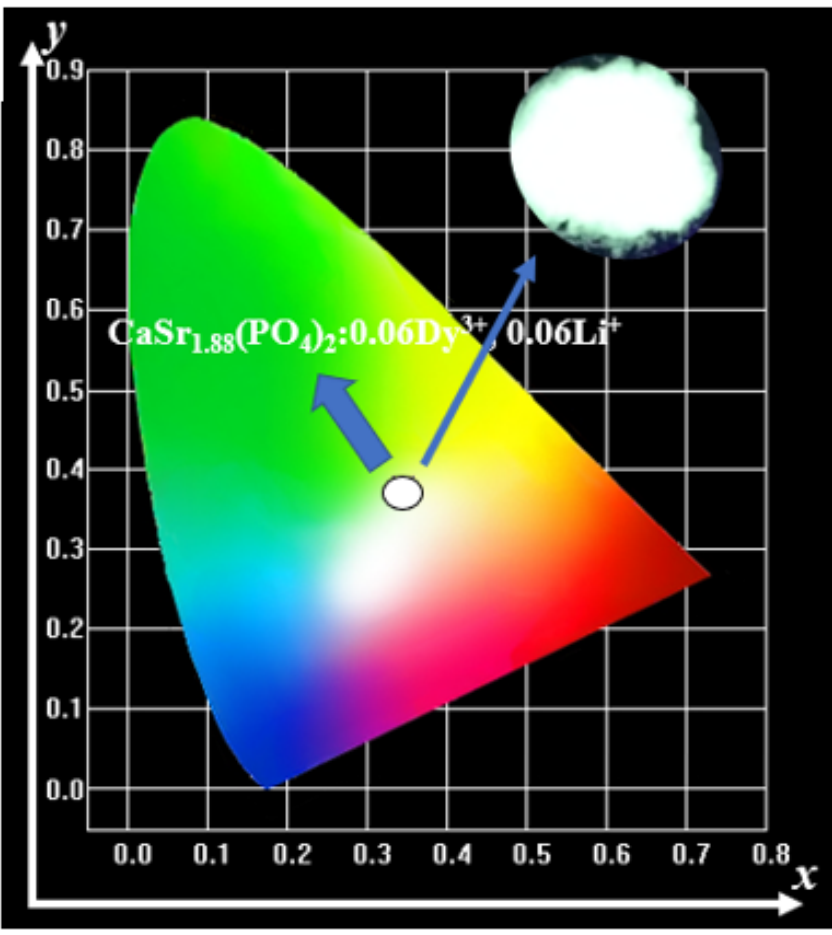

b)

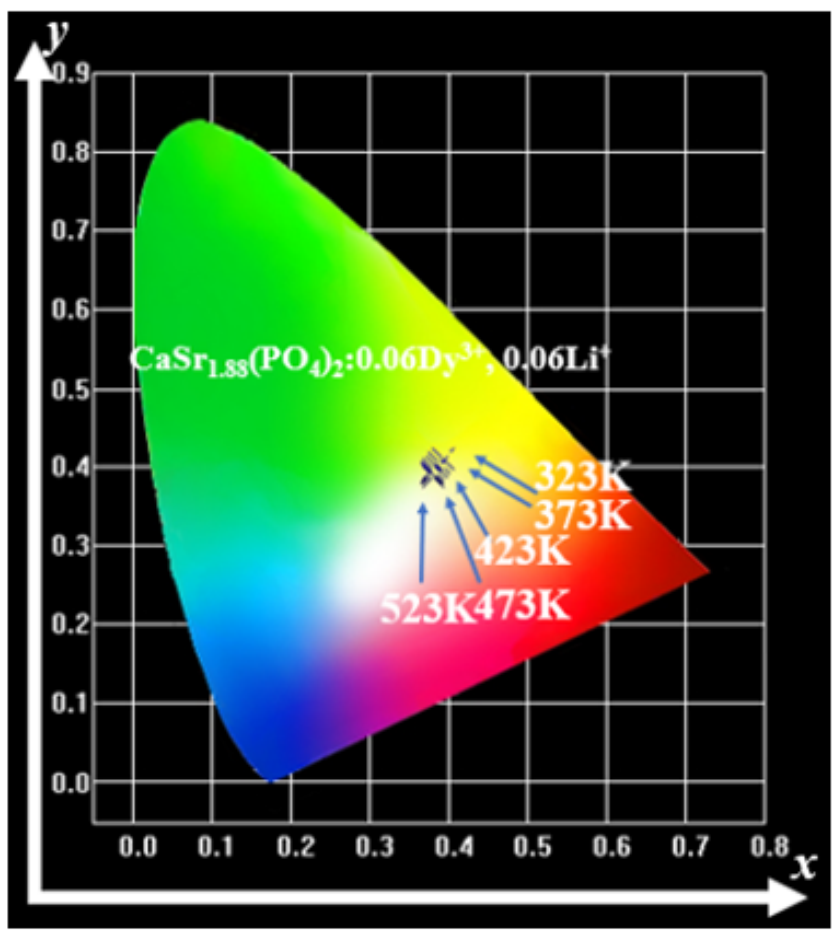

\section{Figure 11}

(a) Chromaticity coordinates for the CaSr1.88(PO4)2:0.06Dy3+,0.06 Li+ material, shown in the CIE diagram; the inset shows a digital photograph of the white-emitting phosphor excited at $351 \mathrm{~nm}$; (b) The $\mathrm{CIE}$ chromaticity coordinates of the Ca2Sr1.88(PO4)2:0.06Dy3+,0.06 Li+ luminophore at different temperature values. 